\title{
Organizar la esperanza En el seminario Juan Gerardi a diez años de su asesinato-martirio, 25 de abril de $1998^{1}$
}

\section{Juan Hernández Pico, Centro de Reflexión Teológica, San Salvador.}

\section{Llamar al mal por su nombre y mirarlo a los ojos}

Voy a hablar sobre la esperanza en este homenaje a Juan José Gerardi en el décimo aniversario de su asesinato. Sería importante, al empezar esta conferencia sobre la esperanza, traer a la imaginación el rostro y el cerebro destrozados del obispo Juan Gerardi; el pecho y el corazón traspasados, por el disparo que lo mató, de Monseñor Óscar Romero; los rostros desfigurados y los cerebros dis persos en la grama de lo que ahora es el Jardín de las rosas, de Ignacio Ellacuría, Amando López y sus compañeros de la UCA, y los cuerpos deshechos de Julia Elba y Celina, las dos mujeres, madre e hija, que con aquellos fueron asesinadas. Y el cuerpo desnudo, flagelado y deformado por la asfixia de Jesús de Nazaret crucificado. Ese cuerpo y esos rostros son la cara espantosa de la maldad humana. Son como unos sacramentos del mal; "misterio operante de iniquidad" (2Tes 2, 7)

Y es que la esperanza hay que vivirla en un mundo donde el mal es inevitable y multipresente. Multipresente y no omnipresente, porque en el desierto de este mundo hay también abundantes oasis de amor y solidaridad.

Afrontar el rostro horrendo y profundamente doloroso del mal es una condi ción previa a poder vivir de esperanza y, por consiguiente, a organizar la espe ranza. Llamar al mal por su nombre y mirarlo a los ojos. Al evocar la memoria histórica, ustedes han estado en este seminario en cierto modo haciendo esto a

1. Me ha inspirado para esta conferencia Andrés Torres Queiruga, en su libro Esperanza a pesar del mal, La resurrección como horizonte, Santander, Sal Terrae, 2005. 
través de los relatos de las terribles experiencias de Chile, de Argentina, de El Salvador y de Guatemala.

Estamos aquí convocados por un asesinato cometido mañana hará diez años. Un asesinato, es decir, quitarle la vida a una persona y, además, hacerlo en una forma cruel y brutal. A una persona inteligente, bondadosa, compasiva, nerviosa, llena de humor y valiente como Juan Gerardi.

La mayoría somos ciudadanos y ciudadanas de este país, Guatemala, donde ha venido habiendo 16 asesinatos diarios o 5.840 asesinatos anuales. Uno de 10 s países más violentos de la tierra. Pero de una tierra donde sólo durante cinco años, en la segunda guerra mundial, se mataron a cincuenta millones de seres humanos, una guerra mundial que no ha dejado de clonarse desde entonces en mil y una guerras en África, en América Latina, en Asia y en Europa, para conformar una auténtica "tercera guerra mundial".

El grito que nos puede brotar de las entrañas es: “¿Dónde está Dios?” Es el grito de Marta y María ante la tumba de su hermano Lázaro, porque toda muerte, incluso la que llamamos natural, por enfermedad y en la cama, es en cierto modo una injusticia: "Señor, si hubieras estado aquî, no habría muerto mi hermano" (Jn 11, 21).

¡Señor, si hubieras estado con nosotros, este mundo sería un paraíso!

¿Qué clase de Dios eres tú que, siendo todopoderoso, no quieres crear un mundo sin mal, un mundo sin codicia, un mundo sin abuso, un mundo sin odio, un mundo sin sangre derramada? ¿Eres acaso un Dios insensible?

¿O qué clase de Dios eres tú que siendo todo bondad, todo misericordioso y compasivo, no puedes crear un mundo sin maldad, un mundo sin codicia, un mundo sin abuso ni opresión, un mundo sin odio ni sangre derramada? ¿Eres acaso un guardián impotente de nosotros y de nuestros hermanos?

La verdad es que Dios no puede crear otros dioses. Dios no puede crear personas humanas que sean todo bondad. Estaría creando robots inhumanos. Dios sólo puede y quiere, con inmenso amor, crear seres humanos, no seres divinos (Gn 1, 31; Sab 11, 23-25).

Dios es todopoderoso porque puede crear el universo, es decir, según las actuales hipótesis de la ciencia, un momento de enorme energía concentrada que puede expandirse a partir de una gigantesca explosión original, y desenvolverse evolutivamente hasta llegar a engendrar personas humanas en una esfera de vida, con libertad, con objetividad y con conciencia, con afectos "ordenados y desordenados" 2 , con solidaridad, con adicciones, con odio, con belleza y con fealdad, y, por supuesto, en todo ello con límites (Gn 2-3).

2. San Ignacio de Loyola, Ejercicios Espirituales, [1]. 
Dios no puede, en cambio, crear un universo de dioses (Gn 3, 4-5). Como tampoco puede crear círculos cuadrados o mieles amargas o hierros de madera o hielos de fuego. Dios no puede crear lo que es lógica y constitutivamente imposible. Es decir — dejando de leer la Escritura fundamentalista y no hermenéutica e históricamente- Dios no puede sacar de las piedras hijos de Abraham (Lc 3, 8), como cualquier mago prestidigitador o ilusionista lo haría en apariencia. Un universo de dioses sería un mito, un Olimpo griego, o sea un monte sublime repleto al mismo tiempo de dioses y diosas a imagen y semejanza de hombres y mujeres, con todos sus vicios. O, peor todavía, un Walhalla soñado por mujeres y hombres como la perfección y el dominio absoluto de una raza sobre las demás de la especie humana. $\mathrm{O}$ una pesadilla de eterna juventud, como la de Fausto, al precio de vender su alma.

Dios no puede hacer personas humanas libres y al mismo tiempo incapaces del mal. La gran paradoja es que la dignidad humana con la que Dios nos ha creado supone la capacidad de elegir en este mundo el bien o el mal, amar u odiar, construir o destruir, ser fiel o infiel, vivir del temor o vivir del amor, aceptar lo diferente o negarlo (Dt 30, 15-20). Algo así dijo Qohelet (el Eclesiastés o Predicador): “Todo tiene su tiempo y sazón... bajo el sol: tiempo de nacer, tiempo de morir; tiempo de plantar, tiempo de arrancar; tiempo de matar, tiempo de sanar; tiempo de derruir, tiempo de construir; tiempo de llorar, tiempo de reír; tiempo de arrojar piedras y tiempo de recogerlas... tiempo de amar, tiempo de odiar; tiempo de guerra, tiempo de paz" (Ecl 3, 1-8).

Sólo nosotros creamos robots electrónicos o clonamos seres vivos. Dios crea personas humanas con su unicidad, cada una o cada uno único e irrepetible, sin ninguna determinación fuera de las de su herencia genética y contexto social, frágilmente libres, pero capaces de forjar su propio destino y también de arruinarlo (Rom 7, 15-8, 1, comparado con Rom 8, 18-22).

Dios crea amorosamente, crea por amor, sale de sí mismo para dar el ser y 1a vida, y nos crea creadores, capaces del gozo y del dolor, y no máquinas condenadas a la felicidad, pero sí personas capaces de irse acercando asintóticamente a la felicidad para ser transfigurados por ella cuando Jesucristo entregue el reino al Padre y acabe con los poderes de este mundo, destruyendo primero al último enemigo, la muerte, para terminar siendo Dios todo en todas las personas (1Cor 15, 24-28).

Y quien quiere hacer en este mundo un paraíso, quien quiere hacer paraísos en la tierra, creyendo copiar una capacidad que Dios no tiene, muestra la mejor patente para fabricar infiernos. Ese fue el resultado de la ilusión de la sociedad sin clases: una fascinante concentración del poder tiránico en el estalinismo y una ingente cadena de campos de concentración de presos y presas. Ese es el resultado del sueño de deificar una raza y una etnia, el holocausto con 6 millones de personas judías gaseadas y 44 millones más de personas muertas; y también 
las ochocientas mil víctimas del genocidio en Ruanda y los nueve millones más desde 1994 hasta hoy. Ese fue el resultado de idolatrar la patria y la seguridad nacional: la Escuela de Mecánica (es decir de tortura) de la Armada en Buenos Aires, los presidios de Tiradentes en Brasil, las cárceles clandestinas de Pinochet en Chile, las doscientas mil víctimas de Guatemala ${ }^{3}$ y las también innumerables de El Salvador. Ese está siendo el resultado de la guerra total contra el terrorismo: las prisiones sin ley ninguna y con tortura justificada, de Guantánamo, Abu Graib y muchas otras clandestinas, y las guerras horrendas, crueles e interminables de Afganistán y de Irak. Y ese es también el resultado de la utopía del mercado benefactor de todos: los cientos de millones de hambrientos, los más de mil millones de desnutridos del planeta, y, ahora en su última crisis, las decenas de miles de viviendas embargadas en los Estados Unidos por incapacidad de pagar sus hipotecas y la especulación financiera centrada en las bolsas de materias primas y de alimentos básicos, que provoca los precios elevados y el aumento del hambre.

\section{El paso humilde a la esperanza}

Mirando al mal a los ojos se puede dar el paso a la esperanza, con gran humildad y paciencia (Rom 8, 24-25), acompañando a la vez la vida y la resistencia de las víctimas. Sin que este paso nos separe ni un momento de sentir las vibraciones del sufrimiento humano, que una y otra vez se nos vuelve inquietante pregunta y clamor, y de solidarizarnos con ellas. Sin que esa compasión y solidaridad - limitadas como son - puedan "invalidar la cruz" (1Cor 1, 17), que es para toda nuestra humanidad, incluido Jesús de Nazaret, este misterio del mal, "el misterio de iniquidad" (2Tes 2, 7). De hecho hay muchos más entre los intelectuales de este mundo, que consideran "locura" a la "cruz" de Jesús de Nazaret (1Cor 1,23), es decir a su muerte prematura por tortura y asesinato en la plenitud de su edad, anunciada como "salvación" y "reconciliación" para la humanidad (2Cor 5, 17-21). Muchos más que entre "los rudos, los oprimidos y los plebeyos" (1Cor 26-28; Mt 11, 25-26 par).

Se puede, pues, como hizo Pablo, anunciar la resurrección como horizonte de la esperanza (1Cor 15; Rom 4, 24-25). Se puede anunciar la resurrección de un crucificado, de una víctima brutal del odio y de la idolatría del poder político y religioso (Hch 2, 23.32, passim). Y se puede comprender que ese anuncio sea "escándalo o locura" para muchos. Pero "fuerza de Dios para los que creen" (1Cor 1, 22-25), buena noticia del amor y de la justicia de Dios, que reivindica a todas las personas que han sufrido una muerte verdaderamente injusta, a todas las víctimas inocentes, y propicia que un día "triunfen las víctimas y no los verdugos", como quería poder esperar Horckheimer, aunque ese triunfo regale "un corazón de carne" también a los verdugos (Ez 36, 26).

3. Véase Comisión de Esclarecimiento Histórico, Guatemala Memoria del Silencio, 1999. 
La resurrección revela al Dios verdadero, es decir, al Dios cuya verdad es la fidelidad, al Dios Padre de Jesucristo, "padre de misericordia y Dios de todo consuelo" (2Cor 1,3) en cuyos brazos Jesús de Nazaret, Juan Gerardi, Oscar Romero, Ignacio Ellacuría, Amando López, Julia Elba y Celina, despiertan de la muerte con la gran sorpresa de su resurrección (Mc 15, 37-39).

La resurrección revela al Dios que estuvo con Jesús de Nazaret toda su vida, y también acompañando su agonía y su muerte (Lc 23,46). Revela al Dios con quien Jesús tuvo una experiencia de bondad y confianza únicas, que tradujo con 1a palabra: padre, abbá (Lc 11, 3; Jn 11, 41-42; Lc 10, 21-22, Mc 14, 35-42 par, passim). La resurrección revela que, respetando la historia, respetando la dignidad humana en ella, sin embargo, más allá de la historia Dios es fiel y no permite ni el triunfo ni la impunidad de la injusticia. Sin resurrección — dice Pablo"somos los más desgraciados" de toda la gente $(1$ Cor 15,19$)$ y de todos los pueblos, porque habríamos creído en un Dios de la impunidad, que deja impune la injusticia. La impunidad no consiste tanto en no condenar a los verdugos, sino sobre todo en no reconocer a las víctimas como inocentes y en no devolverles el honor de su verdad y su propia vida.

Jesucristo resucitado es "el sí de Dios a todas sus promesas" (2Cor 1, 19-20). El sí a la fecundidad, el sí a la abundancia, el sí a la saciedad, el sí a la felicidad, el sî a la solidaridad y el sí a la belleza.

Y ese sí, presentido en su experiencia del Dios abbá, es el que hace a Jesús llamar audazmente felices a los pobres, a los afligidos y a los oprimidos; y, en cambio, desdichados a quienes mantienen la pobreza, causan dolor con crueldad (Lc 6, 20-21) y oprimen a la gente, aunque se disfracen de bienhechores (Lc 22 , 25).

Por el anuncio de la resurrección podemos nosotros aventurarnos en la reflexión teológica - toda teología es una audaz aventura de puntillas al interior del misterio inabarcable de Dios - y llamar a Jesucristo "el testigo fiel" (Ap 1, 5), el mártir auténtico. Jesús de Nazaret, el asesinado, el crucificado, sin dejar de ser asesinado y crucificado, como lo muestran sus llagas en su cuerpo resucitado (Jn 20, 20.27; Ap 5, 6.9), supera este enorme horror e injusticia y se vuelve mártir resucitado.

Juan Gerardi, asesinado vilmente, se vuelve también testigo fiel, mártir de la memoria histórica, testigo de las injusticias que se cometieron abriendo los vientres de las mujeres embarazadas, estrellando niños contra troncos de árboles y quemando vivos a gente reunida para alabar a Dios. Que de todo este horror fue Gerardi testigo fiel en la REMHI (Recuperación de la Memoria Histórica), para que en Guatemala esto no suceda “inunca más!”. Y la Comisión de Esclarecimiento Histórico lo confirmó. 


\section{Construir el reino de la tierra para que venga el reino de Dios y sea creí- ble nuestra esperanza}

Pero la única manera como podemos proclamar la resurrección de Jesús y también la resurrección de Juan Gerardi, no en un futuro final de la historia ni en un ilusorio reino milenario, sino ya desde hoy, desde el día de su crucifixión y de la destrucción de su rostro y cerebro; la única manera como podemos proclamar la resurrección de las víctimas de la soberbia del poder y de la codicia del dinero, de la tortura y del SIDA, del racismo y de la discriminación en este país; la única manera creíble es viviendo vidas diarias como la vida de Jesús y la vida de Gerardi, como la vida de Dios, es decir luchando contra la impunidad de la injusticia y a favor de la justicia "aquí en la tierra como en el cielo" (Mt 6, 10). Así acompaña Dios, por su Espíritu, esta lucha crucial de la humanidad a favor de la justicia. La acompaña silenciosamente, pero con la fuerza enorme del "Señor que es el Espíritu" $(3,17)$, que, "más íntimo a nosotros que nuestra propia identidad" 4 , orando desde nuestra intimidad "con gemidos inenarrables" "cuando nosotros no sabemos cómo orar" (Rom 8, 26-27), y defendiendo nuestra causa ante el mundo (Jn 16, 8-11), poniendo palabras profundamente tradicionales, pero entonces casi inauditas, en los labios de los Padres de Puebla: "La causa de los pobres es nuestra propia causa, es la causa de Cristo" ${ }^{5}$.

$\mathrm{Y}$ en concreto, nuestra esperanza se hará creíble manteniendo vivo o desenterrando, con la actividad indeclinable de la Oficina de Derechos Humanos del Arzobispado de Guatemala (ODHAG), el proceso que los jueces dejaron abierto, en la sentencia condenatoria de varios cómplices en el asesinato de Gerardi, contra varios miembros del antiguo Estado Mayor presidencial. Y escuchando así el grito del Cardenal Arzobispo de Guatemala el pasado domingo, día 20 de abril.

Y también, y sobre todo, luchando por la vida con proyectos de vida para la gente y con la gente.

Y también ayudando a que cambie su imagen de Dios, desde aquella imagen de un Dios intervencionista en nuestra historia diaria a esa otra imagen de un Dios respetuoso de la dignidad de seres humanos libres con la que nos ha creado creadores amorosamente. Que no hay tal vez acción cristianamente más revolucionaria que la de recuperar la imagen de Dios de Jesús de Nazaret para mantenerla eficazmente viva en la cotidianeidad y en la historia.

Nosotros rezamos con el Padre Nuestro, como Jesús: “iVenga tu Reino!” Pero "el Reino de Dios no viene para quienes no construyen el reino de la tierra"6.

4. Frase famosa de San Agustín.

5. Ver Mensaje a los pueblos de América Latina, Madrid, 1982, p. 420.

6. Citado por Herbert Vorgrimler, Karl Rahner Experiencia de Dios en su vida y en su pensamiento, Santander, Sal Terrae, 2004, p. 331. La frase exacta es "El Reino de Dios sólo viene para aquellos que construyen el reino venidero de la tierra". 
La esperanza creyente, "la realidad de las cosas que no vemos" ( $\mathrm{Hbr} 11,1)$, es decir la vida ya aqui en alegría y en felicidad, la vida ya aqui en bondad y en compasión, la vida ya aquí en amor y en valentía, aun dentro de nuestra maldad siempre necesitada de perdón, se hace presente y actual, ahora en la historia y no sólo más allá de la historia, únicamente para los hombres y las mujeres que luchan por la justicia, que respetan la piel de color diferente y los rasgos culturales también diferentes, y que aman a los enemigos mientras se abren a la búsqueda de la verdad, la justicia y el perdón, "buscando así diariamente el reino de Dios y su justicia" (Mt 6, 33).

La esperanza es muy frágil, porque depende de la fe en el Dios de bondad que respeta nuestra libertad en la historia. La esperanza es también muy débil porque depende del amor, es decir de un corazón entrañable, de una mirada de águila pero compasiva, de unos ojos risueños, que sepan luchar por "buscar el Reino y entrar en él" (cfr. Mt 6, 33; Mc 10, 24-27) mientras sonríen con humor frente a lo deslavazado e incompleto de nuestros logros. La esperanza es endeble porque vive de la paciencia, y la paciencia — como he dicho en otro lado- es no sólo la niña pequeña de Péguy, sino también una viejecita cargada de años.

Precisamente porque la esperanza es muy frágil, hay que "organizar la esperanza". Esta era una frase-consigna célebre de un amigo ya difunto, Xabier Gorostiaga. Organizar la esperanza es lo que ustedes han estado haciendo en este seminario. Pero este seminario es sólo el fruto de una siembra larga, profunda y atinada, regada en el cada día.

Para que nuestra esperanza sea creíble, vivámosla en comunidades de solidaridad, organizando también junto con ella la solidaridad nuestra "de cada día" (Lc 11, 3). Así organizaremos la esperanza. La solidaridad y la esperanza son hermanas gemelas. Las dos hacen posible la construcción del reino de la tierra para que venga a nosotros el reino de Dios. Es decir, luchar por la mayor y mejor tierra para los pobres, el mayor y mejor consuelo para los afligidos, la mayor y mejor justicia para los oprimidos, la mayor y mejor paz para los hermanos atormentados por la violencia, y para todos y todas la mayor y mejor compasión, la pasión del amor luchador y solidario (Is 65, 21-23; Mt 25, 31-45; 1Jn 3, 1118) que confía en que Dios nos ama ( $1 \mathrm{Jn} 4,8.19)$, lucha con nosotros a nuestro 1ado, nos respeta y es la sombra protectora que acompaña nuestras vidas: "Yo estaré con ustedes todos los días hasta el fin de la historia" (Mt 28, 20).

Sólo organizando la esperanza y viviéndola en las comunidades cristianas y humanas de base, como hacía Pablo, podremos con él decir, en medio del realismo de la persecución y la hostilidad: “¿Quién nos podrá separar del amor de Dios y de la solidaridad con nuestros hermanos: la mentira, la maledicencia, 1a calumnia, la envidia, la tortura, el secuestro, los asesinatos, el despliegue del poder opresor, la ira de los violentos? Si Dios lucha por la justicia humilde y pacientemente a nuestro lado, ¿quién no luchará? Si Dios resucitó a Jesús y a Juan 
Gerardi y a todas nuestras víctimas que hemos recordado, derrotando la impunidad; si Dios está así con nosotros, ¿quién contra nosotros? Estamos seguros que nada nos podrá separar del amor de Dios en la solidaridad con nuestra gente y en la organización de nuestra esperanza" (cfr. Rom 8, 31-39).

Guatemala, 25 de abril de 2008. 